\title{
THE EFFECT OF NANO-ZINC OXIDE ON PARTICLEBOARD DECAY RESISTANCE
}

\author{
Pouya Marzbani ${ }^{1, \AA}$, Younes Mohammadnia Afrouzi ${ }^{2}$, Asghar Omidvar ${ }^{2}$
}

\begin{abstract}
The aim of this study was to investigate the decay resistance of particleboards treated with nano-zinc oxide against the white-rot fungus Trametes versicolor and the brown-rot species Coniophora puteana. The nanomaterial was used for manufacturing particleboards at 5, 10 and 15\% wt based on the glue dry weight. The soil block decay test was performed according to ASTM D 1413 (2007) using a 12 weeks incubation period. The results showed that all treated boards had good resistance against the decay fungi and the weight loss decreased in the samples with increasing nanomaterial loading. The threshold level of treated boards against fungal decay was obtained about $21 \%$ and $17 \%$ nano- $\mathrm{ZnO}$ against $C$. puteana and T. versicolor, respectively. Therefore, it had a positive effect on increasing particleboard resistance against the fungi. The maximum decay resistance (or minimum weight loss) occurred in the samples containing $15 \%$ zinc oxide nanoparticles.
\end{abstract}

Keywords: Coniophora puteana, decay resistance, nano-zinc oxide, particleboard, Populus deltoides, Trametes versicolor, weight loss.

\section{INTRODUCTION}

Wood is naturally made and consists of carbon hydrates and lignin in its structure. It can be destroyed by different factors such as UV rays, fungi, beetles, ants, marine borers and chemicals (Schmidt 2006). This fact decreases its durability in the wooden structures. Several processes have been suggested to increase the wood durability such as chemical preservation procedures. In recent years, the use of fungicides and insecticides has been met some limitations due to the environmental problems and therefore, the researchers are looking for alternative safe chemicals to increase the wood durability along with minimum damage to the environment (Dorau et al. 2004, Rezaei and Parsapajouh 2004).

Recently, the effects of nanomaterial utilization on improvement of the wood resistance against different wood destructive factors have been investigated in several studies (Clausen 2007, Freeman and McIntyre 2008, Kartal et al. 2009, Yu et al. 2010, Clausen et al. 2010, Clausen et al. 2011, Saha et al. 2011, Sahin and Mantanis 2011, Afrouzi et al. 2013). Nanoscale materials are defined as a set of substances where at least one dimension is less than approximately 100 nanometers (Siegel et al. 1999, Baer et al. 2003, Kafarski 2007). The two main reasons why materials at the nanoscale can have different properties are increased relative surface area and new quantum effects. Nanomaterials have a much greater surface area to volume ratio than their conventional forms, which can lead to greater chemical reactivity and affect their strength.

\footnotetext{
' Department of Pulp and Paper Technology, Faculty of Wood and Paper Engineering, Gorgan University of Agricultural Sciences and Natural Resources, Gorgan, Golestan province, Iran.

${ }^{2}$ Department of Wood Technology and Engineering, Faculty of Wood and Paper Engineering, Gorgan University of Agricultural Sciences and Natural Resources, Gorgan, Golestan province, Iran.

•Corresponding Author: marzbani.pouya@gmail.com

Received: 03.12.2013Accepted: 20.03.2014
} 
Also at the nanoscale, quantum effects can become much more important in determining the materials properties and characteristics, leading to novel optical, electrical and magnetic behaviors (Alagarasi 2011).

Nano-zinc oxide (nano-ZnO) is a white powder that is insoluble in water, but soluble in weak and strong mineral acids, ammonia, acetic acid or formic acid. It is used in many industries due to its low cost and catalytic, electrical, electronic, optical and antimicrobial properties (Sato et al. 2003, Yang et al. 2004). It is used to produce sunscreens, cosmetics, coatings, optical and electronic devices (Yang et al. 2004, Dange et al. 2007). Zinc oxide is used as preservative, but when its particle size is reduced to the nanoscale, its reactivity extremely increases (Mende and MacManus-Driscoll 2007).

Clausen et al. (2009) used vacuum treated southern yellow pine and yellow poplar with 2,5 and 5\% nano$\mathrm{ZnO}$ to evaluate leaching, mold and decay inhibition, termite resistance, and visible signs of weathering. They observed that virtually no leaching occurred at any treatment concentration of nano- $\mathrm{ZnO}$ and all concentrations of the nanomaterial showed inhibition of termite feeding. Decay inhibition was variable. Nano-ZnO did not inhibit the brown rot fungi as well as soluble $\mathrm{ZnSO} 4$ and the weight loss due to the white-rot fungi was inhibited by all tested nano- $\mathrm{ZnO}$ concentrations.

In another research carried out by Kartal et al. (2009), the leachability and efficacy of southern yellow pine treated with copper, zinc, or boron nanoparticles was evaluated against mould fungi, decay fungi, and Eastern subterranean termites. The results showed that nano-copper with or without surfactant, nano-zinc, and nano-zinc plus silver with surfactant resisted leaching compared to metal oxide controls. In addition, the nano-copper treated samples that were exposed to Antrodia sp., resulted in high weight loss (19 to 33 percent) and the unleached samples containing nano-boron and boric acid effectively inhibited all decay fungi. Nano-zinc possessed the most favorable properties such as leaching resistance, termite mortality, and inhibition of termite feeding and decay by white-rot fungi.

The goal of this study was to evaluate the efficacy of particleboards containing zinc oxide nanoparticles against the decay fungi. This is the first study to examine the resistance of particleboard containing nanomaterial against fungal decay.

\section{MATERIAL AND METHODS}

Cottonwood (Populus deltoides) sapwood obtained from the research forest in Shastkalateh, Golestan province, Iran, was chipped and air dried to 3\% moisture content. Urea-formaldehyde glue was used at $12 \%$ wt (based on the wood dry weight). Nano-zinc oxide (Nano Pars Lima Co.) was added at 5, 10 and $15 \%$ wt (based on the glue dry weight) into the glue, mixed by ultrasonic devise UP400S and sprayed on the particles. The mat moisture content was $11 \%$. It was pressed at $175{ }^{\circ} \mathrm{C}$ and a constant pressure of 30 $\mathrm{kg} / \mathrm{cm}^{2}$ for 6 minutes to manufacture the panels with a density of $0,75 \mathrm{~g} / \mathrm{cm}^{3}$. Boards without nano- $\mathrm{ZnO}$ were prepared as control samples. The prepared boards had a thickness of $19 \mathrm{~mm}$ and were cut into 19 mm cubes and tested according to ASTM D 1413 (2007) with 6 replications for each treatment-fungus combination. Water holding capacity of the soil was $130 \%$. The white-rot fungus Trametes versicolor $(\mathrm{L}$.) Lloyd strain (CTB 863 A) and the brown-rot fungus Coniophora puteana (Schumacher ex fries) Karesten (BAM Ebw. 15) were used to inoculate samples. The classification of resistance was done according to ASTM D2017 (2005) method. 


\section{RESULTS AND DISCUSSION}

The results of Tukey statistical analysis test showed that there was a significant difference between WL of treated and untreated samples. Weight loss (\%) was significantly more in the untreated samples and decreased with increasing nanomaterial loading in both fungi tested as shown in Table 1. Variance analysis of the factors affecting WL specified that the independent effect of fungus type and nano-ZnO loading on WL was significant in the $95 \%$ significance level.

The sample resistance against the white-rot fungus significantly increased with increment of nano- $\mathrm{ZnO}$ loading and the minimum WL occurred in the samples containing $15 \%$ nano- $\mathrm{ZnO}$ that was approximately 15 times lower than the untreated sample WL. Improving decay resistance may be due to the antifungal properties of zinc oxide nanoparticles (Kartal et al. 2009).

Table 1. Weight loss due to Trametes versicolor and Coniophora puteana attacks and classification of resistance.

\begin{tabular}{ccccc}
\hline & \multicolumn{2}{c}{ Trametes versicolor } & \multicolumn{2}{c}{ Coniophora puteana } \\
\cline { 2 - 5 } $\begin{array}{c}\text { Nano-zinc oxide } \\
\text { loading (\%) }\end{array}$ & $\begin{array}{c}\text { Weight } \\
\text { Loss } \\
(\%)\end{array}$ & $\begin{array}{c}\text { ASTM D2017 } \\
\text { rating }\end{array}$ & $\begin{array}{c}\text { Weight } \\
\text { Loss } \\
(\%)\end{array}$ & $\begin{array}{c}\text { ASTM D2017 } \\
\text { rating }\end{array}$ \\
\hline 0 & 45,5 & Non-resistant & 39.52 & Moderately resistant \\
5 & 13,93 & Resistant & 16.43 & Resistant \\
10 & 7,78 & Resistant & 12.69 & Resistant \\
15 & 3,03 & Highly resistant & 7.23 & Highly resistant \\
\hline
\end{tabular}

The untreated sample WL due to Trametes versicolor was more than Coniophora puteana. C. puteana as a brown-rot fungus primarily attacks the cellulose and hemicellulose and prefers softwoods while $T$. versicolor, as a simultaneous white-rot fungus, attacks both lignin and carbohydrates and favors hardwoods (Coggins 1980, Harsh and Tiwari 1990, Highley 1991, Curling and Murphy 2002, Schmidt 2006). It may justify more destruction and WL of the untreated samples prepared from poplar sapwood by $T$. versicolor. Higher degradation rate of mannans than cellulose and xylanes may lead to low destruction of hardwoods by C. puteana (Ritschkoff et al. 1992, Schmidt 2006).

A significant reduction occurred in the treated sample WL that was exposed to the brown-rot fungus and there was an inverse relation between WL and nano-ZnO loading. In addition, the treated sample WL due to the brown-rot fungus was more than the samples WL that were exposed to white-rot fungus, although the white-rot fungus can destroy other wood components in addition to lignin (Highley 1991). WL in the samples containing $15 \%$ nano- $\mathrm{ZnO}$ was 3,03 and $7,23 \%$ due to the white and brown rot fungi, respectively. 


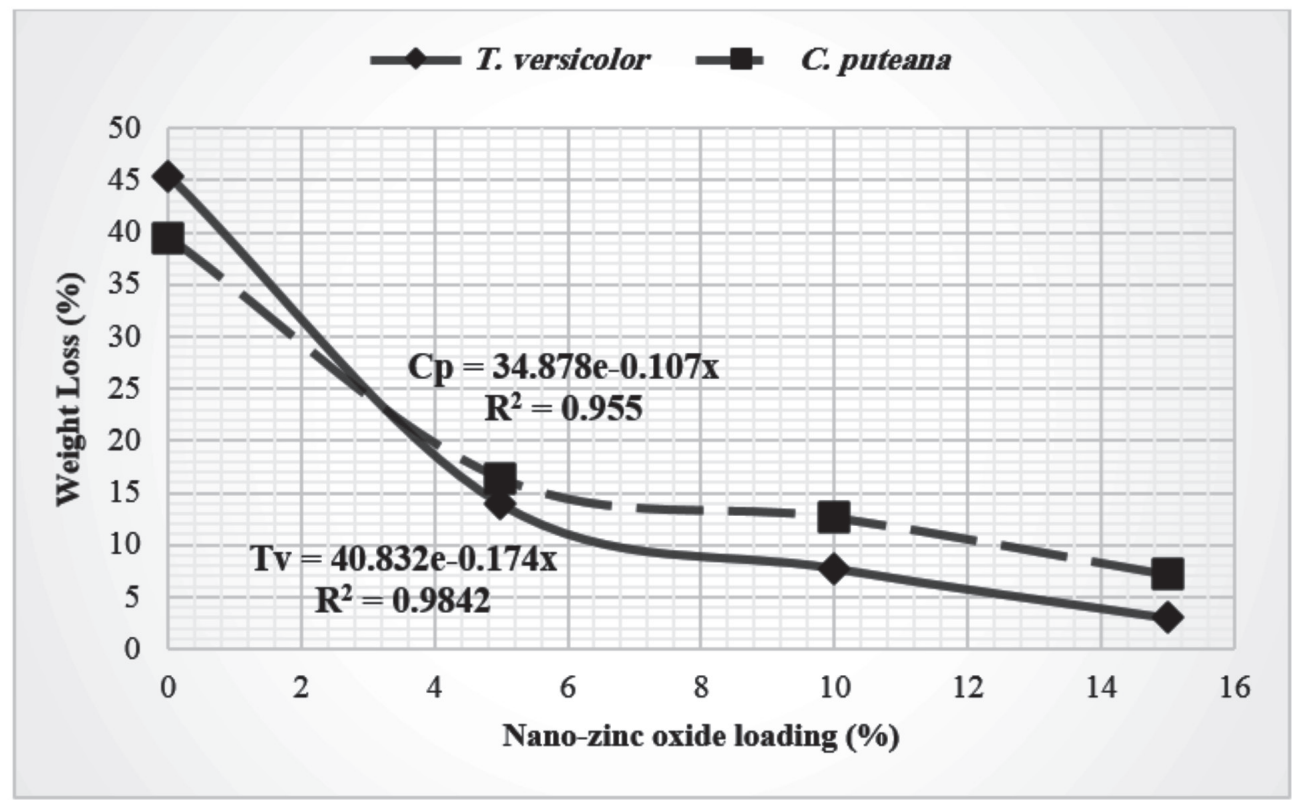

Figure 1. Changes trend of WL and nano-ZnO loading that determines the threshold level of treated boards against Trametes versicolor and Coniophora puteana.

Figure 1 shows the relation between nano-ZnO loading and the board WL for C. puteana and T. versicolor, whereby the threshold level of treated boards obtained about $21 \%$ and $17 \%$ nano- $\mathrm{ZnO}$ against C. puteana and $T$. versicolor, respectively. It means that $C$. puteana had more resistance against nano- $\mathrm{ZnO}$ and it slightly could preserve its destructive activity that resulted in more WL in spite of the antifungal effects of zinc oxide nanoparticles. Therefore, more nanoparticle loading is needed to achieve $0 \% \mathrm{WL}$ in the samples that were exposed to the brown rot fungus. The antifungal properties of nano- $\mathrm{ZnO}$ is related to its interference in the cell wall structure and metabolism process and consequently cell death (Lia et al. 2009).

\section{CONCLUSIONS}

Nano-zinc oxide clearly was effective in the sample weight loss (WL) after exposing to wood destructive fungi. Sample WL decreased with increasing nanomaterial loading. The minimum WL occurred in the boards containing $15 \%$ nano- $\mathrm{ZnO}$ yielding high decay resistance. Nano- $\mathrm{ZnO}$ had good effects on preventing fungal decay and WL due to the white-rot fungus. Therefore, it can be used as a suitable preservative and filler in the wood composites. However, although the exploration of zinc oxide nanoparticles based products is booming in the various directions of consumer products, their comprehensive toxicological impact still remains unclear and should be considered when used for wood. 


\section{REFERENCES}

Afrouzi, Y.M.; Omidvar, A; Marzbani, P. 2013. Effect of Artificial Weathering on the Wood Impregnated with Nano-Zinc Oxide. World Applied Sciences Journal 22 (9): 1200-1203.

Alagarasi, A. 2011. Introduction to nanomaterials. National Centre for Catalysis Research (NCCR) internal bulletin (Unpublished). Chennai, India. [Online]: <http://www.nccr.iitm.ac.in/2011.pdf >

American Society for Testing and Materials. ASTM. 2007. Standard Test Method for Wood Preservatives by Laboratory Soil-Block Cultures. ASTM D 1413. In: Annual Book of ASTM Standards (Vol. 04.10), ASTM International, West Conshohocken, PA.

American Society for Testing and Materials. ASTM. 2005. Standard Test Method for accelerated laboratory test of natural decay resistance for woods. ASTM D 2017. In: Annual Book of ASTM Standards (Vol. 04.10), ASTM International, West Conshohocken, PA.

Baer, D.R.; Amonette, J.E.; Tratnyek, P.G. 2003. Small particle chemistry: reasons for differences and related conceptual challenges. National Nanotechnology Coordinating Office (NNCO) Interagency Research Meeting/Workshop-Nanotechnology and the Environment: Applications and Implications. U.S. Environmental Protection Agency, Washington, D.C., [Online]: <http://epa.gov/ncer/nano/ publications/9-15-2003/presentations.html>

Clausen, C.A. 2007. Nanotechnology: Implications for the wood preservation Industry. International Research Group on Wood Protection, Stockholm, Sweden, Doc. No. IRG/WP 07-30415, p. 10.

Clausen, C.A.; Yang, V.W.; Arango, R.A.; Green III, F. 2009. Feasibility of nano-zinc oxide as a wood preservative. Proceedings of American Wood Protection Association 105: 255-260, San Antonio, Texas, USA.

Clausen, C.A.; Green III, F.; Kartal, S.N. 2010. Weatherability and Leach Resistance of Wood Impregnated with Nano-Zinc Oxide. Nanoscale Research Letters 5(9): 1464-1467.

Clausen, C.A.; Kartal, S.N.; Arango, R.A.; Green III, F. 2011. The role of particle size of particulate nano-zinc oxide wood preservatives on termite mortality and leach resistance. Nanoscale Research Letters 6(1): 465-470.

Coggins, C.R. 1980. Decay of Timber in Buildings Dry Rot, Wet Rot and Other Fungi. Rentokil Limited Felcourt, East Grinstead, UK, p.115.

Curling, S.F.; Murphy, R.J. 2002. The use of the Decay Susceptibility Index (DSI) in the valuation of biological durability tests of wood based board materials. Holz als Roh-und Werkstoff 60(3): 224-226.

Dange, C.; Phan, T.; Andre, V.; Rieger, J.; Persello, J.; Foissy, A. 2007. Adsorption mechanism and dispersion efficiency of three anionic additives [poly (acrylic acid), poly (styrene sulfonate) and HEDP] on zinc oxide. Journal of Colloid and Interface Science 315(1): 107-115.

Dorau, B.; Arango, R.; Green III, F. 2004. An investigation into the potential of ionic silver as a wood preservative. Proceedings of the $2^{\text {nd }}$ Wood-Frame Housing Durability and Disaster Issues Conference. Forest Products Society. Las Vegas, NV, 133-145.

Freeman, M.H.; C.R. McIntyre. 2008. Comprehensive review of copper-based wood preservatives. Forest Products Journal 58(11): 6-27. 
Harsh, N.S.K.; Tiwari, C.K. 1990. Changes in wood components after biodegradation. Material und Organismen 25(2): 137-143.

Highley, T.L. 1991. Degradation of cellulose by brown rot fungi. Proceedings of the $8^{\text {th }}$ International Biodeterioration and Biodegradation Symposium. Elsevier Applied Science, New York. 529-530.

Kafarski, P. 2007. Nanobiotechnology. Forum Akademickie Nr 7(8): 36-37.

Kartal, S.N.; Green III, F.; Clausen, C.A. 2009. Do the unique properties of nanometals affect leachability or efficacy against fungi and termites? International Biodeterioration and Biodegradation 63(4): 490-495.

Lia, J.H.; Hong, R.Y.; Lic, M.Y.; Lib, H.Z.; Zhengd, Y.; Dinge, J. 2009. Effects of ZnO nanoparticles on the mechanical and antibacterial properties of polyurethane coatings. Progress in Organic Coatings 64(4): 504-509.

Mende, L.S.; MacManus-Driscoll, J. 2007. ZnO nanostructures, defects, and devices. Materials Today 10(5): 40-48.

Rezaei, V.T.; Parsapajouh, D. 2004. Investigation on the durability of Acer insigne in normal and treated with a water-soluble salt (ACC) against Coriolus Versicolor. Journal of Agricultural Science 11(1): 53-60 (In Persian).

Ritschkoff, A.C.; Pere, J.; Buchert, J.; Viikari, L. 1992. The role of oxidation in wood degradation by brown-rot fungi. IRG Secretariat, Stockholm, Doc. No. IRG/WP/1562.

Saha, S.; Kocaefe, D.; Sarkar, D. K.; Boluk, Y.; Pichette, A. 2011. Effect of TiO2-containing nanocoatings on the color protection of heat-treated jack pine. Journal of Coating Technology and Research 8(2): 183-190.

Sahin, H.T.; Mantanis, G.I. 2011. Nano-based surface treatment effects on swelling, water sorption and hardness of wood. Maderas. Ciencia y tecnología 13(1): 41-48.

Sato, T.; Tanigaki, T.; Suzuki, H.; Saito, Y.; Kido, O.; Kimura, Y.; Kaito, C.; Takeda, A.; Kaneko, S. 2003. Structure and optical spectrum of $\mathrm{ZnO}$ nanoparticles produced in RF plasma. Journal of Crystal Growth 255(3-4): 313-316.

Schmidt, O. 2006. Wood and Tree Fungi, Biology, Damage, Protection, and Use. Springer-Verlag, Berlin, Heidelberg, Germany, p.334.

Siegel, R.W.; Hu, E.; Roco, M.C. 1999. Nanostructure science and technology. National Science and Technology Council (NSTC), Washington, D.C., p. 336.

Yang, Y.; Chen, H.; Zhao, B.; Bao, X. 2004. Size control of ZnO nanoparticles via thermal decomposition of zinc acetate coated on organic additives. Journal of Crystal Growth 263(1-4): 447-453.

Yu, Y.; Jiang, Z.; Wang, G.; Song, Y. 2010. Growth of ZnO nanofilms on wood with improved photostabilit. Holzforschung 64(3): 385-390. 